\title{
Laurence Moon Bardet Biedl Syndrome: A Rare Case Report in A Tertiary Care Teaching Hospital, Hyderabad, Telangana, India
}

\author{
Pathan Amanulla Khan ${ }^{1}$, Juwerriah Nishaat ${ }^{2}$, Sobia Noor ${ }^{3}$, Naureen Fatima ${ }^{2}$
}

\begin{abstract}
Laurence Moon Bardet Beidl Syndrome is a rare Ciliopathic and Pleiotrophic human Autosomal recessive genetic disorder, which involves affects and effects on multiple organ system. Consanguineous marriage is usually the common cause. The characteristic feature of the disorder are progressive rod cone dystrophy, atypical retinitis Pigmentosa, myopia, central obesity, mental retardation, Anisometropia, Astigmatism, Postaxial Polydactyly, Hypogonadism in males, renal involvement. It affects males and females equally. The treatment of Laurence Moon Bardet Beidl Syndrome is usually directed towards the specific symptoms that are apparent in each individual. We here present a case report of 18 year old male patient presenting in medicine department with weakness of both lower limbs, inability to walk, progressive loss of vision and polydactyly.
\end{abstract}

Key words: Obesity, Hypogonadism, Retinitis Pigmentosa, Para paresis, Mental retardation, rod cone dystrophy

\section{INTRODUCTION}

Pathan Amanulla Khan', Juwerriah Nishaat ${ }^{2}$, Sobia Noor $^{3}$, Naureen Fatima ${ }^{2}$ ${ }^{1}$ Clinical Pharmacist, Wood lands Multi Specialty Hospital, Barkatpura, Hyderabad, INDIA.

2Department Of Pharmacy, AnwarUI-Uloom College of Pharmacy, New Malleypally, Hyderabad, INDIA.

${ }^{3}$ Department of Pharmacy Practice, Anwar-Ul-Uloom College of Pharmacy, New Malleypally, Hyderabad, INDIA.

\section{Correspondence}

Pathan Amanulla Khan

Clinical Pharmacist, Wood lands Multi Specialty Hospital, Barkatpura, Hyderabad, INDIA

E-mail: aman.pathan811@gmail.com

\section{History}

- Submission Date: 01-09-16

- Revised Date: 04-11-16

- Accepted Date: 05-01-17

\section{DOI : 10.5530/ijmedph.2017.1.13}

Article Available online

http://www.ijmedph.org/v7/i1

\section{Copyright}

(C) 2017 Phcog.Net. This is an openaccess article distributed under the terms of the Creative Commons Attribution 4.0 International license.
In 1886 Laurence and Moon explained a case of 7years old female with rod-cone dystrophy, Hypogenitalism, mental retardation, obesity and Polydactyly. Her three elder brothers were also suffering from this clinical state. Then in 1920 Bardet described a female patient of 4 years old presented with the rodcone dystrophy, obesity and polydactyly (11 toes). She also had mental retardation. After two years of Bardet's report i.e., in 1922, Biedl studied two cases and highlighted the complete scenario of clinical signs which includes skull abnormalities, anal Atresia, mental deficiency and gastrointestinal conflicts. In 1925 Solis-Cohen and Weiss connected four patients of one family. Since these discoveries, presence of symptoms such asobesity, hypogonadism, retinal pigment defects, psychological hindrance and Polydactylism in several conditions as combinations, frequently in children with normal parents (cousin marriages) has been termed as Laurence-Moon-Bardet-Biedl Syndrome (LMBBS). ${ }^{1,2}$

Laurence Moon Bardet Biedl Syndrome which is a rare Autosomal genetic disorder with a spectrum of ocular associations such as rod cone dystrophy, (Atypical retinitis Pigmentosa), Myopia, Astigmatism, Anisometropia, Strabismus, keratoconus, optic atrophy, Nystagmus, central obesity, hearing difficulties, hypogonadism in males, renal involvement, postaxial polydactyly. ${ }^{3}$

The patients generally have onset of symptoms within the first 10 years of life and among them the first complaint is usually poor night vision. Constriction of Peripheral visual fields is seen. Changes in the
Fundus include constricted arterioles, waxy disc pallor and changes in the Peripheral Pigment includes pigment atrophy, bone specular pigmentation and areas of white deposits. ${ }^{4}$ Less than $50 \%$ of cases show that males are more commonly affected when compared to females. Recent reports suggest that functional and morphological abnormalities are present in up to $90 \%$ of the affected patients. The renal abnormalities occur with a spectrum of activity, often causing significant morbidity and autopsy data reveals it to be the major cause of mortality. ${ }^{5}$

The other features which are not usually present include hepatic fibrosis, diabetes mellitus, neurological, speech and language disorder, behavioral traits, facial dysmorphism, dental anomalies and developmental delay. ${ }^{6}$

\section{CASE REPORT}

An 18 year old male patient presented to the medicine department with weakness of both lower limbs since 7 days, unable to walk from 7 days and progressive loss of vision since from 1 year. Upon examination the height was $160 \mathrm{~cm}$ weight less than $70 \mathrm{~kg}$. Detailed clinical examination revealed boy of average height moderately built and nourished, obese, lethargic, lying on bed, not moving his lower limbs, having polydactyly. His voice is breathy and with high pitched nasal quality. The ophthalmological examination revealed deteriorating vision due to the retinitis Pigmentosa. The boy was found to be mentally retarded and hypogonadism. He had developmental delay. There was no evidence of hepatic fibrosis or diabetes mellitus in this case. Family history of the 
Table 1: Laboratory Investigation of the Patient

\begin{tabular}{|c|c|c|}
\hline Other examination & Value obtained & Reference range \\
\hline Blood pressure & $110 / 70 \mathrm{~mm} / \mathrm{hg}$ & $120 / 800 \mathrm{~mm} / \mathrm{hg}$ \\
\hline Respiratory rate & 28 cycles/min & $12-20$ cycles/min \\
\hline \multicolumn{3}{|l|}{ Complete blood picture } \\
\hline Laboratory test & Patient's value & Reference value \\
\hline Hemoglobin & $12.5 \mathrm{gm} / \mathrm{dl}$ & Male:11.5-12.5 gm/dl \\
\hline WBC count & $12.5 \times 10^{3} / \mathrm{L}$ & $4,000-11,000$ cells/L \\
\hline Platelet count & $212 \times 10^{3} / \mathrm{L}$ & 1-1.5 lakh cells/L \\
\hline \multicolumn{3}{|c|}{ Normocytic Normochromic with occasional fossil forms. } \\
\hline \multicolumn{3}{|l|}{ Biochemistry report } \\
\hline Random blood sugar & $250 \mathrm{mg} / \mathrm{dl}$ & $70-170 \mathrm{mg} / \mathrm{dl}$ \\
\hline Serum urea & $28 \mathrm{mg} / \mathrm{dl}$ & $15-40 \mathrm{mg} / \mathrm{dl}$ \\
\hline Serum Creatinine & $0.8 \mathrm{mg} / \mathrm{dl}$ & $0.6-1.4 \mathrm{mg} / \mathrm{dl}$ \\
\hline Sodium & $133 \mathrm{meq} / \mathrm{L}$ & $134-148 \mathrm{meq} / \mathrm{L}$ \\
\hline Potassium & $3.4 \mathrm{meq} / \mathrm{L}$ & $3.4-5.4 \mathrm{meq} / \mathrm{L}$ \\
\hline \multicolumn{3}{|l|}{ Urine Analysis } \\
\hline Albumin & Absent & - \\
\hline Sugar & Absent & $0-0.8 \mathrm{mmol} / \mathrm{lit}$ \\
\hline Color & Pale yellow & Pale yellow \\
\hline \multicolumn{3}{|l|}{ Lipid profile } \\
\hline Total cholesterol & $166 \mathrm{mg} / \mathrm{dl}$ & $150-200 \mathrm{mg} / \mathrm{dl}$ \\
\hline VLDL-C & $62 \mathrm{mg} / \mathrm{dl}$ & $2-30 \mathrm{mg} / \mathrm{dl}$ \\
\hline HDL-C & $42 \mathrm{mg} / \mathrm{dl}$ & $40-60 \mathrm{mg} / \mathrm{dl}$ \\
\hline LDL-C & $62 \mathrm{mg} / \mathrm{dl}$ & $2-30 \mathrm{mg} / \mathrm{dl}$ \\
\hline Triglycerides & $308 \mathrm{mg} / \mathrm{dl}$ & $<150 \mathrm{mg} / \mathrm{dl}$ \\
\hline \multicolumn{3}{|l|}{ Thyroid profile } \\
\hline FT4 & $1.14 \mathrm{ng} / \mathrm{dl}$ & $0.61-1.12 \mathrm{ng} / \mathrm{dl}$ \\
\hline TSH level & $2.89 \mathrm{microlitr} / \mathrm{ml}$ & $0.34-5.60 \mathrm{microlitr} / \mathrm{ml}$ \\
\hline
\end{tabular}

patient reveals that his father and mother had a consanguineous marriage. The patient is having one brother with similar features, which were consistent with LMBBS. His brother is also obese and is following a similar episodes of illness. ${ }^{7}$

The birth history of the patient revealed that he was born out of interrelative marriage his mother was normal during pregnancy and had no history of taking any medications during gestation period. He was born at full term by normal vaginal delivery. History of birth asphyxia, cyanosis, feeding difficulties was negative. The baby was immunized peroliodically. According to the patient's mother baby had delayed physical and mental growth with delayed developmental milestones. He was started walking at the age of 4 years and spoke when he was around 5 years old. He gained weight with little or no delay. Genetic tests were not done because of the non-availability of the test in our institute and poor socioeconomic status of the patient. ${ }^{1}$

Echo Doppler studies showed mitral valve, aortic valve, pulmonary valve, tricuspid valve were normal. Left atrium is $2.2 \mathrm{~cm}$, left ventricleEDD is $4.0 \mathrm{~cm}$, and PW is $1.0 \mathrm{~cm}$. Right atrium, right ventricle was normal, aorta $2.0 \mathrm{~cm}$, pulmonary artery is normal, IAS and IVS is intact, good LV/RV function and normal sized chambers, normal valves, no PE/ clot/vegetation.

Clinical Neuropathy EMG reports revealed no CMAP in right common peroneal nerve. The CMAP amplitude is reduced and the other parameters are within normal limits in right posterior tibial nerve. The distal latencies CMAP amplitude and motor conduction velocities are within normal limits in right median and ulnar nerve. F-wave latencies are within normal limits. No SNAP's (sural nerve action potential) could be elicited in right median amplitude is reduced and sensory conduction velocity is within normal limits in right Sural nerves.

Nerve conduction study (NCS) is the medical diagnostic commonly used to evaluate the function, especially the ability of electrical conduction of the motor and sensory nerves and muscles of human body. It indicated when there is pain in limbs, weakness from spinal nerve compression and mainly for evaluation of weakness of arms and legs. Motor NCS and sensory NCS was performed in patient by electrical stimulation of peripheral nerve and recording from muscle and sensory portion of supplied by the nerve respectively. F-wave study here was performed to evaluate the conduction of action potential in the segments of the limb.

\section{DISCUSSION}

Laurence Moon Bardet Biedl Syndrome is an uncommon disorder. It is an Autosomal recessive disorder. Both parents must be carriers of defective gene and both must pass on that defective gene to the child in the order for the child to get affected. If both individual carry the defective gene, which is responsible for causing LMBBS, there is 1 in 4 chances of having a child with this syndrome. ${ }^{7}$

Recent advances in genetics have enabled the investigators to define the syndrome by some specific mutations. Eleven genes are known to 
be associated with this syndrome and those are BBS1, BBS2, ARL6/ BBS3, BBS4, BBS5, MKKS/BBS6, BBS7, TTC8/BBS8, B1/BBS9, BBS10, TR1M32/BBS11.This syndrome is transmitted as an Autosomal recessive trait from the parents. There is a considerable heterogeneity and intra familial variation in the extent and severity of clinical manifestations of LMBBS. The diagnosis of LMBBS is established by clinical criteria. ${ }^{8}$
The Treatment of Laurence-Moon-Biedl-Biedl syndrome is directed toward the specific symptoms that are present in each individual. Treatment may require the coordinated efforts of a team of pediatricians, orthopedic surgeons, pathologists, audiologist, ophthalmologists, nephrologists, and other healthcare professionals. Individuals with this syndrome needs to undergo a regular ophthalmologic examinations as well as periodic as-

Table 2: EMG reports

\begin{tabular}{|c|c|c|c|c|c|c|c|}
\hline $\begin{array}{l}\text { Nerve/sites } \\
\text { Motor NCS:- } \\
\text { R-medium-APB }\end{array}$ & Rec-site & Lat Ms & Amp Mv & Seg amp \% & Segments & Distance $\mathrm{Cm}$ & Velocity $\mathrm{m} / \mathrm{sec}$ \\
\hline Wrist & $\mathrm{APB}$ & 3.28 & 10.3 & 100 & Wrist APB & 7 & - \\
\hline Elbow & APB & 8.13 & 7.5 & 72.2 & Elbow-wrist & 23 & 47 \\
\hline \multicolumn{8}{|l|}{ R-UInar-ADM } \\
\hline Wrist & $\mathrm{ADM}$ & 2.4 & 5.5 & 100 & Wrist-ADM & 7 & - \\
\hline Elbow & $\mathrm{ADM}$ & 7.97 & 5.2 & 93.6 & B-Elbow wrist & 30 & 54 \\
\hline \multicolumn{8}{|c|}{ R-Common Peroneal-EDB } \\
\hline Ankle & EDB & NR & NR & NR & Ankle-EDB & 8 & - \\
\hline \multicolumn{8}{|l|}{ R-Tibial (knee)-AH } \\
\hline Ankle & $\mathrm{AH}$ & 6.51 & 0.6 & 100 & Ankle-AH & 8 & - \\
\hline Knee & $\mathrm{AH}$ & 15.94 & 0.1 & 10.5 & Knee-ankle & 38 & 40 \\
\hline \multicolumn{8}{|l|}{ F-Wave:- } \\
\hline \multirow[t]{2}{*}{ Nerve } & M Lat ms & & $\mathrm{F} \min \mathrm{ms}$ & & F-M ms & & \\
\hline & left & right & left & right & Left & right & \\
\hline Median-APB & - & 3.28 & - & 29.58 & - & 26.30 & \\
\hline Ulnar-ADM & - & 2.24 & - & 28.44 & - & 26.20 & \\
\hline Tibial (knee)-AH & - & 5.52 & - & 61.93 & - & 56.41 & \\
\hline \multicolumn{8}{|l|}{ Sensory NCS } \\
\hline Nerves/sites & Rec-site & $\begin{array}{l}\text { Onset Lat } \\
\mathrm{ms}\end{array}$ & PP Amp $\mu v$ & segments & Distance cms & Onset velocity m/s & \\
\hline \multicolumn{8}{|l|}{ R- median-digit 11} \\
\hline Wrist & 11 & NR & NR & Wrist 11 & 11 & NR & \\
\hline \multicolumn{8}{|l|}{ R-ulnar-Digit 5} \\
\hline Wrist & Digit 5 & NR & NR & Wrist digit 5 & 11 & NR & \\
\hline \multicolumn{8}{|l|}{ R- sural-last malleolus } \\
\hline 1 & Last malleolus & 2.29 & 2.5 & 1-last Malleolus & 10 & 43.6 & \\
\hline
\end{tabular}

\section{Table 3: Modified diagnostic criteria for Bardet-Biedl syndrome6}

\begin{tabular}{|c|c|}
\hline Primary features & Secondary features \\
\hline Rod cone dystrophy & Speech disorder/delay \\
\hline Polydactyly & Strabismus/cataracts/astigmatism \\
\hline Obesity & Brachydactyly/Syndactyly \\
\hline Learning disabilities & Developmental delay \\
\hline Hypogonadism in males & Polyuria/Polydipsia(Nephrogenic Diabetes Insipidus) \\
\hline \multirow[t]{6}{*}{ Renal anomalies } & Ataxia/poor coordination/imbalance \\
\hline & Mild spasticity \\
\hline & Diabetes mellitus \\
\hline & Dental crowding/Hypodontia/Small roots/High arched palate \\
\hline & Left ventricular hypertrophy/Congenital Heart disease \\
\hline & Hepatic fibrosis \\
\hline
\end{tabular}


sessments to determine the presence of any complications potentially associated with this disorder such as kidney dysfunction, diabetes mellitus, liver function and high blood pressure. Early intervention is important in ensuring that children with Laurence-Moon-Bardet-Biedl syndrome reach their highest potential. Genetic counseling may be of benefit for affected individuals and their families. ${ }^{6}$ The treatment which was given to the patient was Inj Methyl Prednisolone, Inj Opti-neuron, for 25 days then later Inj Immunoglobulin was added to the therapy.

Prevalence range in North America and Europe ranges from 1:140,000 to 1:160,000 live births. However in Kuwait and Newfound land the rate is much higher with an estimated incidence of $1: 13,500$ and $1: 17,500$ respectively. There is a high frequency of consanguineous marriages in Pakistan, especially in Pathans and ethnic groups. ${ }^{\text {? }}$

Particularly puberty is a stressful time for those with this syndrome and referring the patient to an experienced counselor is usually helpful. Testosterone supplements are oftenly prescribed to male patients, specifically in cases of having low level of this hormone. There are no proven effective treatments to either prevent or alleviate the deterioration in vision. However, spectacles were advised as low vision was present and regular ophthalmologist follow up was stressed upon. ${ }^{9}$ The IQ tests determines that only a less number of patients are mentally retarded. The decreased IQ levels are correlated with the presence of visual handicap. ${ }^{10}$

In general BBS patients are happy and friendly living children, and the society should not have a discriminatory attitude towards these children so that their quality of life may be improved. The patients had been seen by several specialists in different facilities, the diagnosis had been missed, possibly because of the rarity of the condition. It was the hypogonadism, absence of sexual characters. There was weakness of lower limbs and patient was unable to walk since 7 days and also there was progressive loss of vision since 1 year that brought the patient to over the department, where diagnosis was made. The case is being reported for its rarity. ${ }^{9}$

Initial investigation and follow up recommendations for a person with Bardet-Biedl Syndrome ${ }^{6}$

\section{Baseline:}

Electroretinogram (ERG)/ visually evoked Responses (VER)

Renal ultrasound

Intravenous Pyelogram (IVP) or DMSA/DPTA scans

ECG \& echocardiogram

Prader-Willi syndrome exclusion by molecular testing

Consider:

CT/MRI brain scan/renal

Electroencephalogram (EEG)

Statementing of educational needs

Registration of blindness

Speech assessment \&therapy

Six monthly:

Urine analysis (dipstick)

\section{CONCLUSION}

The patient showed all the principal features of infrequent Autosomal recessive disease called Laurence Moon Bardet Biedl Syndrome. Diagnosis of this syndrome is missed because of its rarity. Pediatricians and other specialties need to have adequatein formation on LMBBS for accurate diagnosis due to its conflicting prognosis. Parents of the patient were counseled and called for regular follow-up to observe whether there are any progressive developmental changes and for behavioral therapy. The patient was also given testosterone supplementation as per Endocrinological consultation. Accessory digits are often non- functional and may be excited. Obesity is area of major concern in these patients and if left uncontrolled, will lead to multiple health problems. A low calorie and low protein diet help in obesity control and may also slow the progression of renal failure in patients with BBS. The patient was advised diet control as per Nutritionist recommendations and physical exercises.

\section{ACKNOWLEDGEMENT}

I have taken efforts in this case report. However, it would not have been possible without the kind support and help of many individuals. I would like to extend my sincere thanks to all of them.

I would like thank my co-authors Dr. Sobia Noor, Juwerriah Nishaat and Naureen Fatima for their efforts, co-operation and for being constant source of encouragement in completing this report.

My thanks and appreciation also go to people who are directly and indirectly helped us out in developing the case report.

\section{CONFLICT OF INTEREST}

I (we) certify that there is no conflict of interest with the patient or any other organisation regarding this case report.

\section{ABBREVIATIONS USED}

LMBBS: Laurence Moon Bardet Biedl Syndrome; EDD: End Diastolic Dimension; PW: Pulsed Wave; IAS: Intra arterial Septum; IVS: Intra ventricular Septum; LV/RV: left ventricle / right ventricle; PE: Pulmonary Embolism; EMG: Electromyogram test; CMAP: Compound Muscle Action Potential test; SNAP: Sural Nerve Action Potential; NCS: Nerve Conduction Study; ERG: Electroretinogram; VER: Visually Evolved Responses; IVP: Intravenous Pyelogram; DMSA/DPTA: Dimercaptosuccinic acid test; CT/MRI: computerized Tomography/Magnetic Resonance Imaging.

\section{REFERENCES}

1. Mariam A, Tariq A, Samer A, Rukhsana AS, Laurence Moon Bardet Biedl Syndrome With Anaemia. J Ayub Med Coll Abbottabad. 2014;26(4):625-7.

2. Dr. Rajasekhar P, Dr. Parmi MK, Dr. Aalekhya PS. International Journal of Science and Research (IJSR) ISSN (online) : 2319-7064, Index Copernicus Value (2013) : 6.14| Impact Factor (2013):4.438,4(2):2015.

3. Bijnya BP, Anusha V, Rashmi RD, Jyotiranjan M, Susanta P. Unusual pattern of RefractiveError In Siblings of Laurence-Moon-Biedl Syndrome, J of Evidence Based Med and Hlthcare, pISSN- 2349-2562, eISSN- 2349-2570/Nol.2/Issue 33/Aug. 17, 2015, Page 5053.

4. Tariq Q, Ayub ARN, Mehmooda A. Laurence-Moon (Bardet) Biedl Syndrome, JKPractioner 2003;10(3):217-218, Vol. 10 No. 3, July- Sept 2003.

5. Bryan W, David J, John W. Chronic renal failure; an important feature of the Laurence-Moon-Biedl syndrome. Postgraduate Medical Journal. 1988;65:462-4.

6. Lokesh S, Vinod k, Supreethi k. Bardet biedl syndrome- A case report, Indian journal of Basic and Applied Medical Research; P ISSN:2250-284X, E ISSN : 2250-2858. 2014:4(1):425-8

7. Amanullah A, Nazish B, Baseer S, Munir SM. Hypokalemic Paralysis and Megaloblastic Anaemia in Laurence-Moon- Bardet-Biedl syndrome. Journal of the College of Physicians ad Surgeons Pakistan. 2009;19(4):186-8.

8. Sahu JK, Jain V. Laurence-Moon-Bardet-Biedl Syndrome. J Nepal Med Assoc. 2008;47(172):235-7.

9. Sumir K, Bharat BM, Jyotistema M. Bardet- Biedl syndrome: A rare case report from North India. Indian J Dermatol Venereol Leprol. 2012;78:228.

10. Azizul MH, Sharmin LS, Tarikul QI, ARM Safiuddin E. Bardet Biedl syndrome-A Case Report. The Journal of Teachers Association RMC Rajashahi. ISSN 10198555. 2007;20(1):56-9.

Cite this article : Khan PA, Nishaat J, Noor S, Fatima N. Laurence Moon Bardet Biedl Syndrome: A Rare Case Report in A Tertiary Care Teaching Hospital, Hyderabad, Telangana, India. Int J Med. Public Health. 2017; 7(1): 68-71. 